\title{
Lateral Compression Behavior of High-Strength and High-Elastic-Modulus Fibers and Influence of Environment*
}

\author{
Kohji MINOSHIMA**, Yoshihiro MAEKAWA***, \\ Tetsuya YAMADA ${ }^{* * *}$ and Kenjiro KOMAI**
}

In this paper, we describe the quasi-static lateral compression tests of highstrength, high-elastic-modulus fibers. The fibers examined were $\gamma$-alumina fiber (Altex) by Sumitomo Chemical Co., Ltd., two types of carbon fibers by Mitsubishi Rayon Co., Ltd., and four types of aramid fibers by Du Pont and Teijin Ltd. Special attention was paid to environmental influences such as water absorption and electron or ultraviolet radiation on the lateral compression behavior of aramid fibers. A specially designed testing machine (load range: $0.1 \mathrm{mN}-5 \mathrm{~N}$, accuracy: $0.02 \mathrm{mN}$ ) that enables mechanical testing, including fatigue of microelements, was employed. Using the testing machine, lateral compression of fibers whose diameter ranged from 7 to 17 $\mu \mathrm{m}$ was achieved with sufficient precision. The transverse compression behavior of carbon fibers and alumina fiber exhibited brittle nature: most of the load-displacement curve followed the elastic deformation, with a final catastrophic fracture into small pieces. However, that of the aramid fibers showed a more ductile nature: the very early stage of the load-displacement curve was elastic, and the rest was plastic. The final catastrophic fracture observed in ceramic and carbon fibers did not occur with a large amount of plastic deformation. The influence of electron radiation on the transverse elastic modulus of aramid fibers was not observed. However, water absorption or ultraviolet radiation lowered the transverse elastic modulus. The fiber surface was closely examined using an atomic force microscope, and the influence of environment on surface degradation and deformation behavior is discussed.

Key Words: Lateral Compression, Single Fiber Test, Fracture, Environmental Influence, Water Absorption, Electron Radiation, Ultraviolet Radiation, Atomic Force Microscopy, Nanofractography, Carbon Fiber, Alumina Fiber, Aramid Fiber

\section{Introduction}

Most composite materials are composed of matrix materials such as polymer, metal, or ceramics

* Received 3rd June, 1999. Japanese original: Trans. Jpn. Soc. Mech. Eng., Vol. 65, No. 631, A (1999), p. 454460 (Received 18th June, 1998)

** Department of Mechanical Engineering, Graduate School of Engineering, Kyoto University, YoshidaHonmachi, Sakyo-Ku, Kyoto 606-8501, Japan. Email: minoshima@mech.kyoto-u.ac.jp

*** Toyota Motor Corporation, Toyota-Cho 1, Toyota 471-8571, Japan

**** Sanwa Bank, Fushimi-Cho 3-5-6, Chuo-Ku, Osaka 541-8530, Japan and reinforcements including high-strength, high-elastic-modulus fibers, the diameter of which is of the order of $\mu \mathrm{m}$. The mechanical properties of such composite materials are dependent on the properties of the matrix, the fiber and the fiber/matrix interface: the mechanical properties of the fiber itself in small diameter must be evaluated ${ }^{(1),(2)}$ in order to evaluate the strength of the composite material as well as to design a composite structure and develop a new composite material. Considering these, it is very important to develop a micromechanical testing machine for $\mu \mathrm{m}$-sized fibers, as well to investigate the fatigue properties $^{(3)}$ and the environmental influence on the mechanical properties ${ }^{(4)}$.

Besides the above considerations, micromaterials 
such as fibers are of the order of $\mu \mathrm{m}$; therefore, damage that causes fracture and degradation in strength is in extremely localized and small areas, compared with conventional $\mathrm{mm}^{-}$sized mechanical parts. Therefore, higher magnification, or nanometric surface damage evaluation ${ }^{(5),(6)}$, for example, using an atomic force microscope (AFM), is required, instead of conventional $\mu \mathrm{m}$-order damage evaluation using e.g., a scanning electron microscope (SEM).

In this investigation, lateral compression tests were conducted using a specially designed micromechanical testing machine developed by the authors ${ }^{(7),(8)}$, in carbon fibers, ceramic fiber, and aramid fibers, which are used as typical reinforcements of composite materials. Special attention is paid to the effects of environmental influence of water absorption and electron or ultraviolet radiation on the lateral compression behavior of aramid fibers. Surface damage was closely examined using an SEM and an AFM, and then the deformation behavior of the fibers and the effects of environment are discussed.

\section{Experimental Procedures}

Table 1 summarizes the longitudinal mechanical properties of the fibers tested ${ }^{(4),(9)}$. The table also shows the manufacturers' data ${ }^{(10)-(13)}$ in parentheses. Seven fibers were used: two types of carbon fibers, high strength type, Pyrofil $\mathrm{T}-1$, and intermediate modulus type, Pyrofil MM-1, both of which were manufactured by Mitsubishi Rayon Co., Ltd.; ceramic fiber or $\gamma$-alumina fiber, Altex, by Sumitomo Chemical Company Ltd. ; and four types of aramid fibers, Kevlar 29, Kevlar 49 and Kevlar 149 by Du Pont Ltd., and Teijin's Technora.

Lateral compression tests were conducted using a specially designed micromechanical testing machine developed by the authors, which enables mechanical testing, including fatigue, of a microelement ${ }^{(7),(8)}$.

Table 1 Properties of carbon, alumina, and aramid fibers. Manufacturers' data are shown in parentheses.

\begin{tabular}{|c|c|c|c|}
\hline Fiber & $\begin{array}{c}\text { Diameter, } \\
\mu \mathrm{m}\end{array}$ & $\begin{array}{c}\text { Longitudinal Tensile } \\
\text { Strength, GPa }\end{array}$ & $\begin{array}{c}\text { Longitudinal Elastic } \\
\text { Modulus, GPa }\end{array}$ \\
\hline Carbon Fiber & & $(3.53)$ & $(235)$ \\
Pyrofil T-1 & 7 & $(3.43)$ & $(294)$ \\
Pyrofil MM-1 & 7 & $2.15(1.8)$ & $215(210)$ \\
\hline $\begin{array}{l}\gamma \text {-Al }{ }_{2} 0_{3} \text { Fiber } \\
\text { Altex }\end{array}$ & 17 & & \\
\hline Aramid Fiber & & $2.98(2.9)$ & $69(72)$ \\
Kevlar 29 & 13 & $2.91(2.8)$ & $91(109)$ \\
Kevlar 49 & 13 & $2.15(2.3)$ & $117(144)$ \\
Kevlar 149 & 13 & $3.20(3.04)$ & $60(70)$ \\
Technora & 12 & & \\
\hline
\end{tabular}

Small loads are applied by means of an electromagnetic actuator, and the resultant displacement is measured with a differential transformer. The main specifications of the testing machine are: load range: $0.1 \mathrm{mN}-5 \mathrm{~N}$; loading accuracy: $0.02 \mathrm{mN}$; maximum displacement: $250 \mu \mathrm{m}$; displacement measuring accuracy: $0.1 \mu \mathrm{m}$. For the lateral compression tests, a press plate (micro-Vickers hardness: 689 HMV0.2713 HMV0.2) was used instead of a three-point bending jig. The loading stylus used was a truncated conical diamond tip $50 \mu \mathrm{m}$ in diameter. The roughness $R_{a}$ of the press plate measured using an AFM was $1.9 \mathrm{~nm}$, which was smooth enough to conduct lateral compression tests for fibers with diameter of the order of $\mu \mathrm{m}$. The compressive loading rates selected were $20.8 \mathrm{mN} / \mathrm{s}$ for carbon and Altex fibers and $3.7-3.9$ $\mathrm{mN} / \mathrm{s}$ for aramid fibers. The transverse elastic modulus was calculated from the relationship between the lateral compressive load and the resultant displacement of the loading stylus.

For carbon and ceramic fibers, tests were conducted in fibers conditioned in laboratory air, whereas for aramid fibers, the fibers conditioned both in laboratory air and in deionized water at $80^{\circ} \mathrm{C}$ for 40 to 50 days and those irradiated by electron or ultraviolet rays were used, and will be referred to as waterabsorbed or electron or ultraviolet-irradiated fiber, respectively: the fibers conditioned in laboratory air were irradiated for $1.0 \times 10^{4} \mathrm{~s}$ by electrons at $1.5 \mathrm{MeV}$ produced in a Van de Graff type electron accelerator (Mitsubishi Electric Corp., VE20). The fibers were placed on a carbon fiber reinforced composite material (CFRP, AS-4/PEEK), and then both were irradiated by electrons in laboratory air. The CFRP used was conductive, and the total absorbed dose was measured using an integrating ammeter connected to the CFRP. The total absorbed dose of the CFRP was $4000 \mathrm{Mrad}$. During the radiation, the samples were air-cooled, and the temperature was maintained at about $60^{\circ} \mathrm{C}$.

The source of ultraviolet radiation was a black lamp (mean wavelength: $350 \mathrm{~nm}$, NEC Corp., BL-B), with wave power of $116.6 \mathrm{~W} / \mathrm{m}^{2}$, which was twice that of sunlight. The fibers were then irradiated for $3.0 \times$ $10^{5} \mathrm{~s}$. The fiber surfaces after a lateral compression test and that obtained by interrupting a test, were examined using a thermoelectron-emission-type (JSM-5400 LV, JEOL) and a field-emission-type (S4500, Hitachi Ltd.) scanning electron microscope. Nanoscopic fiber surface damage was evaluated in laboratory air using an atomic force microscope (AFM, Digital Instruments, NanoScope III and multiprobe SPM system), operating under the contact mode. 


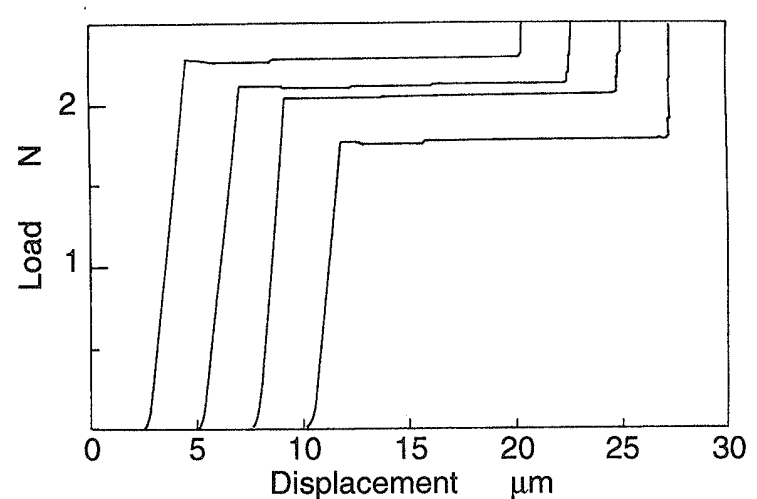

Fig. 1 Load-displacement curves of alumina fiber, Altex.

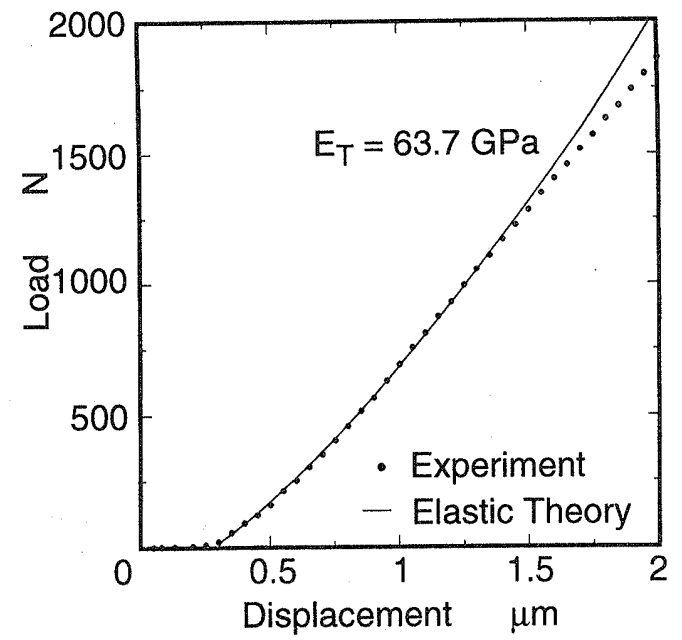

Fig. 2 Least squares fit of the initial lateral load-displacement curve of alumina fiber, Altex, to the theoretical elastic load-displacement curve ${ }^{(14),(15)}$.

\section{Experimental Results and Discussions}

\subsection{Lateral compression behavior of the fibers preconditioned in air}

Figure 1 illustrates an example of the relationship between load and displacement of four different Altex fibers. Figure 2 shows the least squares fit of a set of experimental results in a lower load range to a theoretical load-displacement curve, which was obtained by assuming that the fiber was isotropic in a plane normal to the fiber direction. These figures indicate that lateral compression tests were precisely conducted in fibers with diameter of the order of $\mu \mathrm{m}$. In the case of inorganic fibers such as carbon fibers and Altex fiber, the load-displacement curve at an extremely low load level exhibited non-elastic behavior, which was caused by uneven contact among the loading stylus, the lower press plate and the testing fiber. However, the load-displacement curve became elastic, and most of the curve followed the elastic deformation: the elastic region in inorganic fibers was larger than that observed in aramid fibers, as will be shown later. Figure 3 shows an SEM image of a

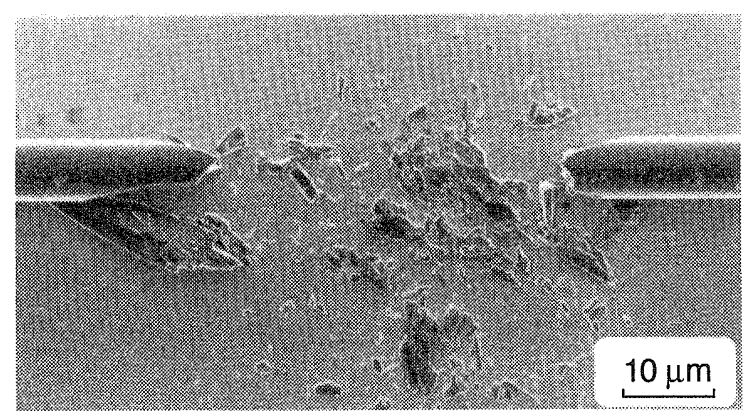

Fig. 3 Lateral compression fracture behavior (Carbon fiber, $\mathrm{T}-1$ ).

broken carbon fiber of $\mathrm{T}-1$, indicating that the carbon fibers and Altex fiber broke in a brittle manner without any plastic deformation, and then into small pieces.

Figures 4 and 5 show typical load-displacement curves of an aramid fiber conditioned in laboratory air and the least squares fit of the initial experimental curve to a theoretical one. Figure $4(\mathrm{a})$ shows the load-displacement curve in the entire testing load range of 0 to $4.5 \mathrm{~N}$, whereas Figs. $4(\mathrm{~b})$ and $4(\mathrm{c})$ show intermediate and initial loading ranges of up to $500 \mathrm{mN}$ and of up to $100 \mathrm{mN}$, respectively. In the case of aramid fibers, the load-displacement curve was elastic in the initial loading range of only $20-30 \mathrm{mN}$ (see Figs. 4(c) and 5), and then the fibers deformed plastically without catastrophic fracture into small pieces (see Fig.6). This deformation was observed irrespective of water absorption and electron or ultraviolet radiation.

The transverse elastic moduli were calculated by a least squares fit of experimental data to a theoretical load-displacement curve. The results of the fibers conditioned in laboratory air are presented in Table 2. As for anisotropic property of the fiber, the $E_{L} / E_{T}$ ratio of Altex fiber was about three and was smaller than those of carbon fibers and aramid fibers which gave $E_{L} / E_{T}$ ratios of 20 to 40 , indicating that Altex fiber has a more isotropic nature. In the case of carbon fibers, $E_{L}$ of MM-1 was higher than that of T-1, whereas $E_{r}$ of $\mathrm{MM}-1$ was lower than that of T-1. This is due to the carbonization- and graphitizationinduced crystal orientation ${ }^{(16)}$.

In the case of aramid fibers, the $E_{L} / E_{T}$ ratio increased in the order of Kevlar 29, Kevlar 49 and Kevlar 149, i.e., with an increase in $E_{L}$ of the fiber. This indicated that anisotropy of the fiber is promoted with an increase in $E_{L}$. As shown before, aramid fibers exhibited ductile deformation behavior without brittle catastrophic failure, which was observed in carbon fibers and Altex fiber. In the case of Kevlar fibers, plastic deformation was observed, showing 
Table 2 Transverse elastic modulus of the fibers preconditioned in air.

\begin{tabular}{|c|c|c|c|c|c|c|c|}
\hline & \multicolumn{2}{|c|}{ Carbon Fiber } & Alumina & \multicolumn{4}{|c|}{ Aramid Fiber } \\
\cline { 2 - 7 } & $\mathrm{T}-1$ & MM-1 & Fiber, Altex & Kevlar 29 & Kevlar 49 & Kevlar 149 & Technora \\
\hline $\begin{array}{c}\text { Longitudinal Elastic } \\
\text { Modulus } E_{\mathrm{L}, \mathrm{GPa}}\end{array}$ & 235 & 294 & 215 & 69 & 91 & 117 & 60 \\
\hline $\begin{array}{c}\text { Transverse Elastic } \\
\text { Modulus } \mathrm{ET}_{\mathrm{T}}, \mathrm{GPa}\end{array}$ & 11.2 & 9.4 & 66.1 & 2.77 & 2.83 & 3.06 & 1.68 \\
\hline $\mathrm{E}_{\mathrm{L} / \mathrm{ET}}$ & 21 & 31 & 3.3 & 25 & 32 & 38 & 36 \\
\hline
\end{tabular}

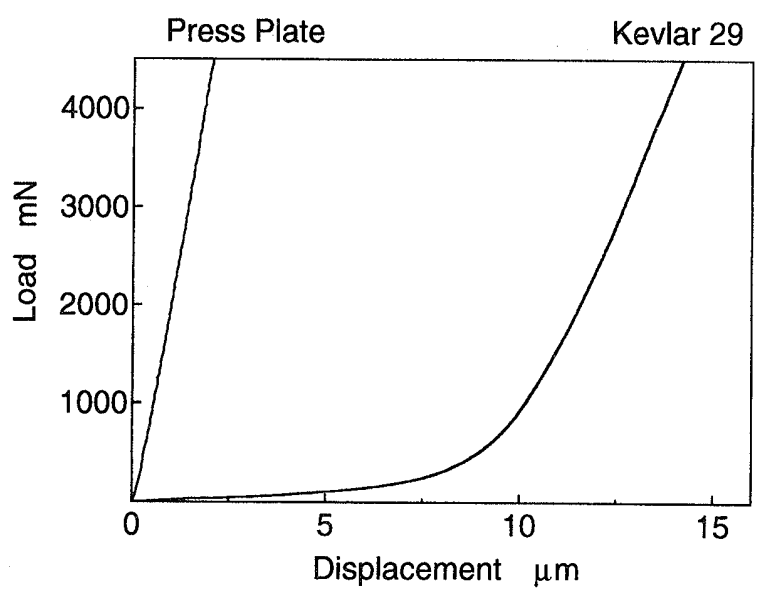

(a) Loading range: $0-4.5 \mathrm{~N}$

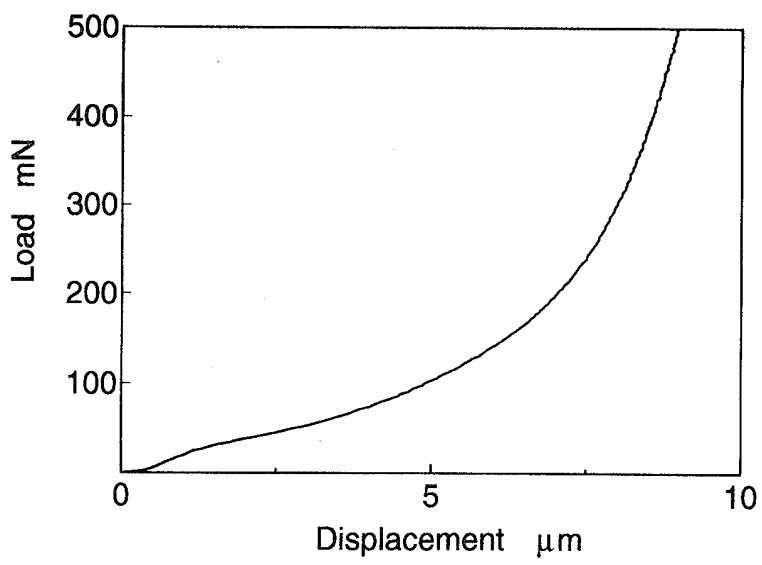

(b) Loading range: $0-500 \mathrm{mN}$

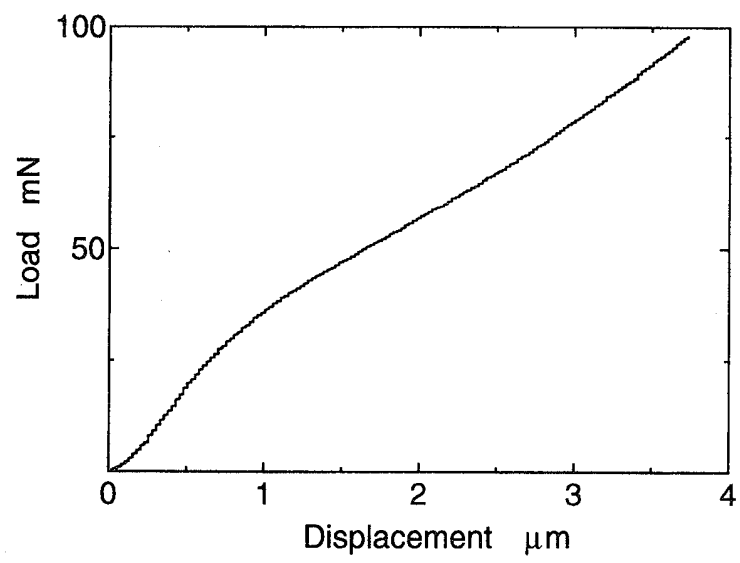

(c) Loading range: $0-100 \mathrm{mN}$

Fig. 4 Load-displacement curves of Kevlar 29 fiber. The fiber was preconditioned in air.

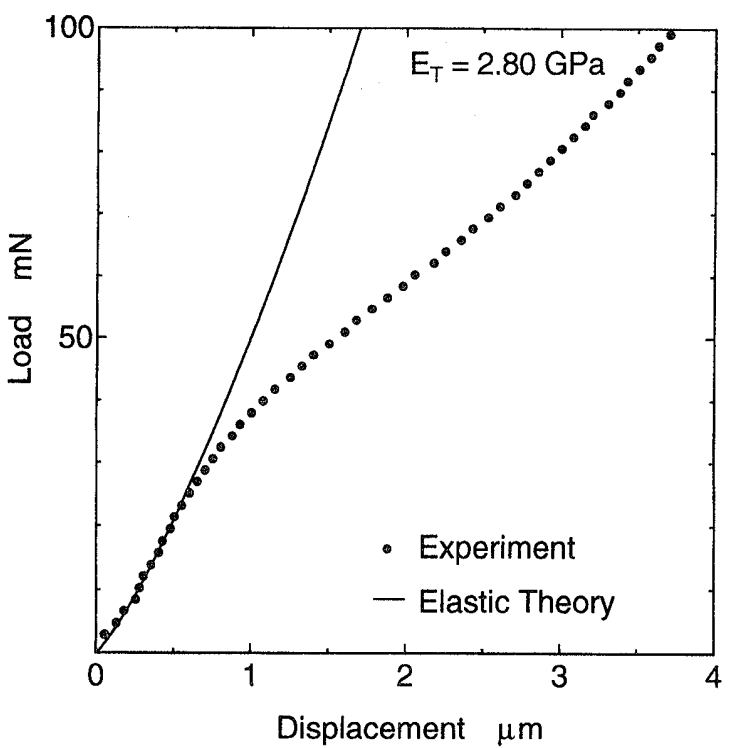

Fig. 5 Least squares fit of the initial lateral load-displacement curve of aramid fiber, Kevlar 29, to the theoretical elastic load-displacement curve ${ }^{(14),(15)}$.

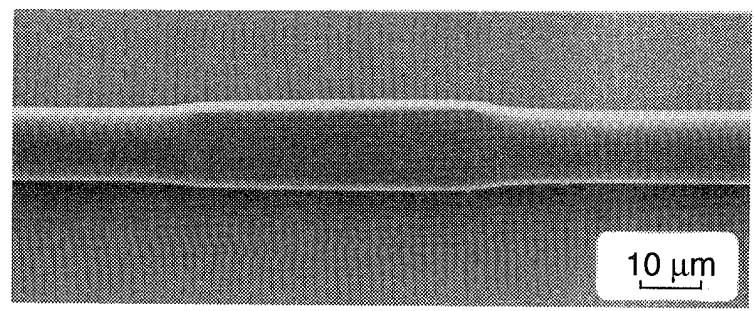

(a) Interrupted at $100 \mathrm{mN}$

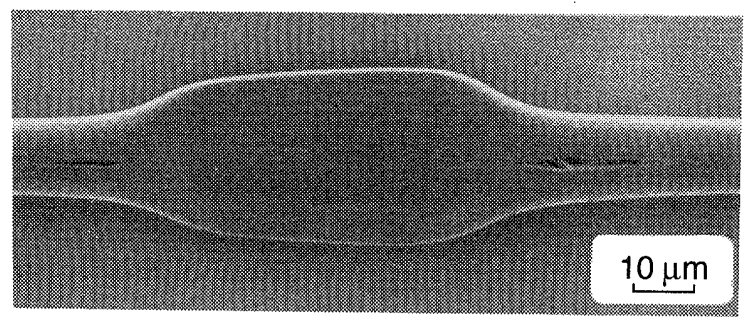

(b) Interrupted at $600 \mathrm{mN}$

Fig. 6 Lateral compression induced deformation behavior (Aramid fiber, Kevlar 29, preconditioned in air).

cracks initiated at both ends of the compression site. Similarly to Kevlar fibers, Technora fiber deformed plastically without catastrophic fracture. However, no crack was initiated and propagated at the compression site, although a maximum load of $4900 \mathrm{mN}$ of the testing machine was applied to the fiber. This is because the elongation of failure of Technora fiber was higher and the fiber was less susceptible to fiber splitting compared with Kevlar fibers.

\subsection{Effect of environment on lateral compres-} sion behavior in aramid fibers

Tables 3 and 4 summarize the effects of water absorption and electron or ultraviolet radiation on the 
Table 3 Effects of water absorption on the transverse elastic properties of aramid fibers.

\begin{tabular}{|c|c|c|c|c|}
\hline & Kevlar 29 & Kevlar 49 & Kevlar 149 & Technora \\
\hline Transverse Elastic Modulus, GPa & 1.91 & 2.29 & 2.74 & 1.46 \\
ET,water (Preconditioned in Water) & $(0.22)$ & $(0.25)$ & $(0.47)$ & $(0.05)$ \\
\hline Transverse Elastic Modulus, GPa & 2.77 & 2.83 & 3.06 & 1.68 \\
ET, air (Preconditioned in Air) & $(0.21)$ & $(0.27)$ & $(0.45)$ & $(0.16)$ \\
\hline$E_{T, \text { water }} \mathrm{ET}_{\mathrm{T}, \text { air }}$ & 0.69 & 0.81 & 0.90 & 0.87 \\
\hline Water Gain, \% & 5.3 & 4.3 & 2.1 & 0.80 \\
\hline
\end{tabular}

Ten sampies for each test.

Values in parentheses indicate standard deviation.

Table 4 Effects of electron and ultraviolet radiation on the transverse elastic properties of aramid fibers.

\begin{tabular}{|c|c|c|c|c|}
\hline & Kevlar 29 & Kevlar 49 & Kevlar 149 & Technora \\
\hline $\begin{array}{c}\text { Transverse Elastic Modulus, GPa } \\
\mathrm{E}_{\mathrm{T}, \mathrm{el}} \text { (Electron Irradiated) }\end{array}$ & $\begin{array}{r}2.79 \\
(0.50)\end{array}$ & $\begin{array}{c}2.78 \\
(0.31)\end{array}$ & $\begin{array}{c}2.99 \\
(0.32)\end{array}$ & $\begin{array}{c}1.61 \\
(0.20)\end{array}$ \\
\hline $\begin{array}{c}\text { Transverse Elastic Modulus, GPa } \\
E_{T, \text { ul (Ultraviolet Irradiated) }}\end{array}$ & $\begin{array}{c}2.11 \\
(0.22)\end{array}$ & $\begin{array}{c}2.44 \\
(0.17)\end{array}$ & $\begin{array}{c}2.65 \\
(0.41)\end{array}$ & $\begin{array}{c}1.55 \\
(0.13)\end{array}$ \\
\hline 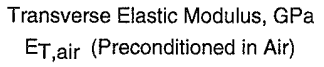 & $\begin{array}{c}2.77 \\
(0.21)\end{array}$ & $\begin{array}{c}2.83 \\
(0.27)\end{array}$ & $\begin{array}{l}3.06 \\
(0.45)\end{array}$ & $\begin{array}{c}1.68 \\
(0.16)\end{array}$ \\
\hline $\mathrm{E}_{\mathrm{T}, \mathrm{el}} / \mathrm{E}_{\mathrm{T} \text {, air }}$ & 1.01 & 0.98 & 0.98 & 0.96 \\
\hline $\mathrm{E}_{\mathrm{T}, \mathrm{u} /} / \mathrm{E}_{\mathrm{T}, \mathrm{air}}$ & 0.76 & 0.86 & 0.87 & 0.92 \\
\hline
\end{tabular}

Ten samples for each test.

Values in parentheses indicate standard deviation.

lateral compression behavior of aramid fibers. Table 3 also shows the equilibrium water sorption at $80^{\circ} \mathrm{C}^{(4)}$. Irrespective of the fiber used, $E_{T}$ decreased when the fiber absorbed water. This decrease tended to become larger as the fiber absorbed more water. This decrease was, in particular, large in Kevlar 29. An SEM observation, performed by interrupting the tests, shows that the amount of fiber splitting was more conspicuous in fibers conditioned in water than those conditioned in air. The authors et al. ${ }^{(4),(17),(18)}$ reported that the longitudinal elastic modulus of aramid fiber is decreased by water absorption. A similar environmental effect was obtained in the transverse elastic modulus of aramid fibers.

In contrast, the effect of electron radiation on the transverse elastic modulus in aramid fibers was not observed (Table 4). However, ultraviolet radiation decreased the transverse elastic modulus, irrespective of the fiber used. This decrease was particularly large in Kevlar 29 fiber.

\section{3 Nanoscopic AFM surface damage evaluation of aramid fibers}

Figure 7 illustrates examples of AFM images of aramid fibers, i.e., Kevlar 29 and Technora fibers, conditioned in laboratory air. The images were taken before lateral compression tests and therefore represent the virgin fiber. The fiber surfaces of Kevlar 29 and Kevlar 49 were smooth when observed using an SEM. However, nanoscopic surface images taken by an AFM showed a longitudinal fibril structure, typical of aramid fibers ${ }^{(4),(19)}$. In contrast, the surface of Technora fiber exhibited nodular structures (see Fig. 7

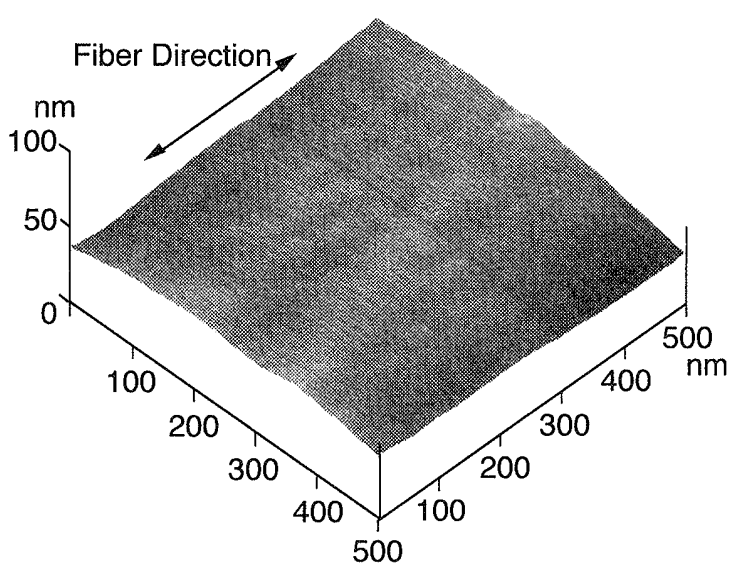

(a) Kevlar $29\left(R_{a}=0.73 \mathrm{~nm}\right)$

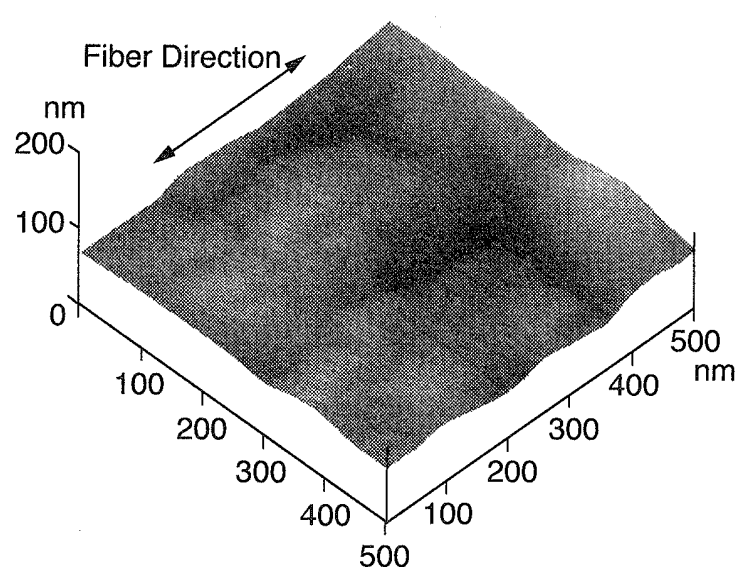

(b) Technora $\left(R_{a}=3.55 \mathrm{~nm}\right)$

Fig. 7 Aramid fiber surface, imaged using an atomic force microscope (Virgin fiber surface, preconditioned in air).

(b)). The roughness $R_{a}$ of Technora fiber, obtained from a $1 \mu \mathrm{m} \times 1 \mu \mathrm{m}$ area, was $3.55 \mathrm{~nm}$, which was larger than those obtained in Kevlar fibers: the roughness, $R_{a}$, of Kevlar 29, Kevlar 49 and Kevlar 149, was $0.73 \mathrm{~nm}, 0.67 \mathrm{~nm}$ and $1.33 \mathrm{~nm}$, respectively. This indicates that Technora fiber has a rough surface that contributes to the high interfacial strength due to the anchoring effect, or mechanical bonding, when it is used as a reinforcement in a composite material.

For water-absorbed fiber, nodule-type surface damage was observed, as reported elsewhere ${ }^{(4)}$. The diameter of the nodules ranged from about $30 \mathrm{~nm}$ to $500 \mathrm{~nm}$. These nodule-type damages were considered to be caused by water absorption into fiber through the fiber molecules. They promoted fiber splitting of water-absorbed fibers, resulting in a decrease in fiber strength and elastic modulus in both longitudinal and transverse directions.

Figure 8 illustrates an AFM image of the Kevlar 49 fiber surface irradiated by electrons. Irrespective of the fiber used, nodule-type damage was observed on the entire fiber surface. The largest nodule was about 


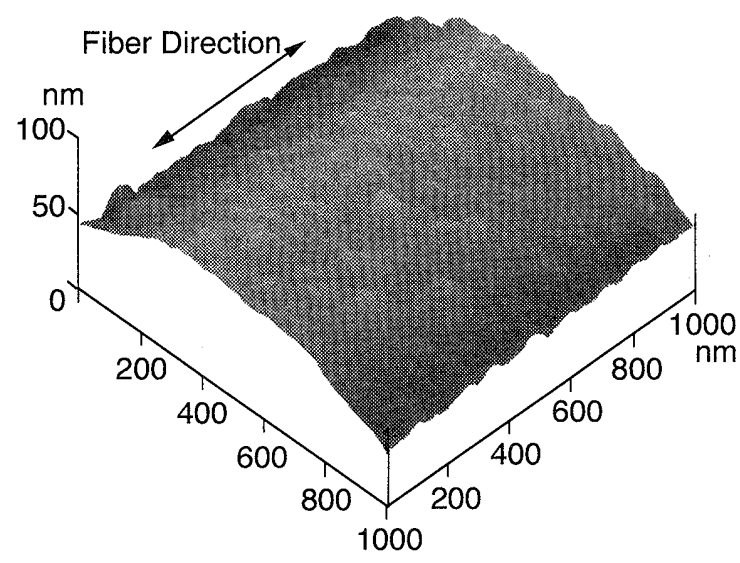

Fig. 8 Aramid fiber surface of Kevlar 49, imaged using an atomic force microscope (electron-irradiated fiber surface).

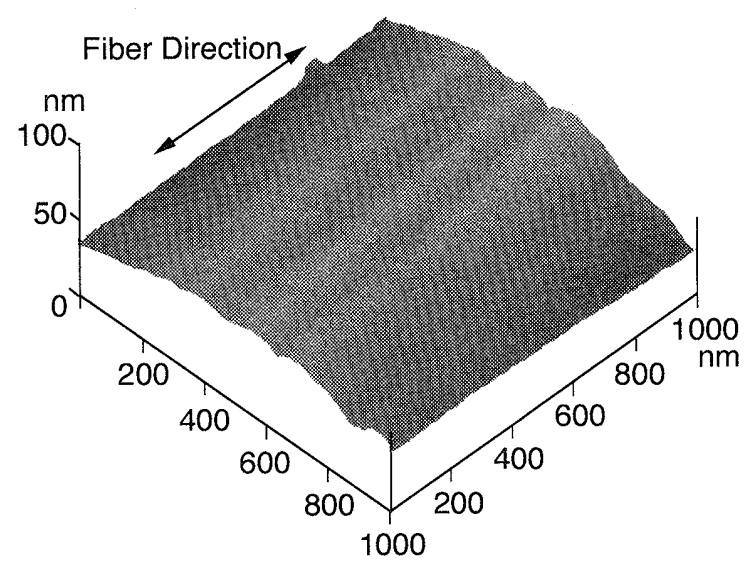

Fig. 9 Aramid fiber surface of Kevlar 49, imaged using an atomic force microscope (ultraviolet-irradiated fiber surface).

$100 \mathrm{~nm}$ in diameter and 10 to $20 \mathrm{~nm}$ in height, and was smaller than those observed on the fiber surface immersed in water. This agreed with the finding of no effect of electron radiation, whereas both longitudinal and transverse elastic moduli were decreased by water absorption.

In contrast, a longitudinal-groove-type damage about $10 \mathrm{~nm}$ deep was observed on the surface of the fiber irradiated by ultraviolet rays. However, no such groove was observed within a $10 \mu \mathrm{m}$ width along the circumference of the fiber, and there the fiber surface was similar to that of virgin fiber. In the case of ultraviolet exposure, such grooves may induce a decrease in both transverse and longitudinal elastic moduli as well as fiber strength. The mechanisms of the decrease in elastic modulus and fracture strength caused by such nanometric fiber surface damages should be further investigated by, for example, in situ nanometric fiber surface damage observation and/or interrupted tests.

\section{Conclusions}

Single-fiber lateral compression tests were conducted in carbon fibers, ceramic fiber and aramid fibers using a specially designed micromechanical testing machine developed by the authors. Special attention was paid to the effects of environment on the lateral compression behavior in aramid fibers, including water absorption and electron or ultraviolet radiation. Surface damage was closely examined using an atomic force microscope, and nanoscopic fiber surface damage was evaluated. This investigation yielded the following conclusions.

1. Using the developed micromechanical testing machine, lateral compression tests in a single fiber of 7 to $12 \mu \mathrm{m}$ diameter could be performed in a precise manner.

2. Carbon fiber and ceramic fiber fractured in a brittle and catastrophic manner into small pieces, and most of the load-displacement curve followed the elastic deformation. In contrast, aramid fiber exhibited more ductile deformation: the very early stage of load-displacement curve was elastic, and the rest was plastic. Final catastrophic fracture observed in ceramic and carbon fibers did not occur with a large amount of plastic deformation.

3. The $E_{L} / E_{T}$ ratio of $\gamma$-alumina (Altex) fiber was about three and was smaller than those of carbon fibers and aramid fibers, which ranged from 20 to 40 , indicating that the Altex fiber had a more isotropic nature. In the case of carbon fibers, $E_{L}$ of MM-1 was higher than that of $\mathrm{T}-1$, whereas $E_{T}$ of $\mathrm{MM}-1$ became lower than that of $\mathrm{T}-1$. This is due to carbonizationand graphitization-induced crystal orientation.

4. Irrespective of the aramid fiber used, $E_{r}$ decreased when the fiber absorbed water, similar to the case of the longitudinal elastic modulus and the fiber strength. In the case of water-absorbed fiber, nanoscopic nodule-type fiber surface damage was observed, which was successfully imaged using an AFM. This surface damage caused a decrease in the elastic modulus and fiber strength by water absorption.

5. The influence of electron radiation was hardly observed on the transverse elastic modulus in aramid fibers. Electron radiation induced nodule-type fiber surface damage of the nanometer order. However, such nodules were smaller than that induced by water absorption. This is consistent with the finding that no influence of electron radiation was observed, whereas the transverse and longitudinal elastic moduli were decreased by water absorption. In contrast, the transverse elastic modulus was decreased by ultraviolet radiation. In this case, longitudinal-groove-type damage was observed using an AFM. 


\section{Acknowledgments}

The appropriation of Grants-in-Aid from the Scientific Fund of the Ministry of Education, Science, Sports and Culture of the Japanese Government (Contract Nos.: 06452148, 08650107) is appreciated. Thanks are extended to Mr. S. Imao of Mitsubishi Rayon Co., Ltd., Mr. K. Yamatsuta of Sumitomo Chemical Company Ltd., and Mr. S. Sakamoto of Toray Kevlar Company for the donation of the sample materials of carbon fibers, alumina fibers, and aramid fibers, respectively.

\section{References}

(1) e.g., Bourgain, E. and Masson, J.J., Compos. Sci. Technol., Vol. 43 (1992), p. 221.

(2) e.g., Kawabata, S., Jour. Text. Inst., Vol. 81 (1990), p. 432.

(3) Minoshima, K., Maekawa, Y. and Komai, K., Submitted to International Journal of Fatigue.

(4) Minoshima, K., Tsuru K. and Komai, K., Trans. Jpn. Soc. Mech. Eng., Vol. 63, No.614, A (1997), p. 2142.

(5) Sumiyoshi, E., Matsuoka, S., Ishikawa, K. and Nihei, M., Trans. Jpn. Soc. Mech. Eng., Vol. 57, No. 541, A (1991), p. 2237.

(6) Minoshima, K. and Komai, K., Materials Science Research International, Vol. 2 (1996), p. 209.

( 7 ) Komai, K., Minoshima, K., Tawara, H., Inoue, S. and Sunako, K., Trans. Jpn. Soc. Mech. Eng., Vol. 60, No. 569, A (1994), p. 52.

(8) Komai, K., Minoshima, K., Inoue, S. and Fujii, H., Trans. Jpn. Soc. Mech. Eng., Vol.62, No. 596, A (1996), p. 978.

(9) Komai, K., Minoshima, K. and Mishima, T., Trans. Jpn. Soc. Mech. Eng., Vol. 61, No. 586, A (1995), p. 1153.

(10) Carbon Fibers and Carbon Fiber Reinforced Composite Materials (Pyrofil), Mitsubishi Rayon Technical Reports.

(11) "Altex" Alumina Fiber, Sumitomo Chemical Co., Ltd.

(12) Aramid Fibers, Technical Report, DTK-TO1 91. 2., Toray Kevlar Co., Ltd.

(13) Teijin Technical Reports.

(14) Hadley, D.W., Ward, I.M. and Ward, J., Proc. Roy. Soc., A285 (1965), p. 275.

(15) Pinnock, P.R., Ward, I.M. and Wolfe, J.M., Proc. Roy. Soc., A291 (1966), p. 267.

(16) Fitzer, E. and Heine, M., Fiber Reinforcements for Composite Materials, (1988), p. 73, Elsevier Science Publishers.

(17) Morgan, R.J., Pruenda, C.O., Butler, N., Kong, F.M., Caley, L. and Moore, R.L., URCL-89625, 1983.

(18) Abbott, N.J., AFML-TR-74-65, Part III, (1975).

(19) Yang, H.Y., Fiber Reinforcements for Composite Materials, (1988), p. 249, Elsevier Science Publishers. 